\title{
Semimembranosus Muscle
}

National Cancer Institute

\section{Source}

National Cancer Institute. Semimembranosus Muscle. NCI Thesaurus. Code C52987.

One of the three muscles that compose the hamstring muscles (semitendinosus, semimembranosus, bicepsfemoris); it is located in the posterior compartment of the thigh, and originates from the ischial tuberosity, inserts on the medial tibial condyle, and functions, in conjunction with the other muscles of the hamstring group, to extend the leg at the hip and to flex the leg at the knee. 